\title{
STUDI KOMPARASI PEMILIHAN ANGKA KECEPATAN KENDARAAN DI PURWOKERTO DAN SEMARANG
}

\section{Comparation Study of Vehicle Speed Selection in Purwokerto and Semarang}

\author{
Probo Hardini \\ Jurusan Teknik Sipil \\ Fakultas Teknik \\ Universitas Jenderal Soedirman \\ Jl. Mayjen. Sungkono Km 5 \\ Kalimanah, Purbalingga \\ Jawa Tengah \\ probo.hardini@unsoed.ac.id
}

\author{
Nurul Hidayati \\ Program Studi S2 Teknik Sipil \\ Fakultas Teknik, Universitas \\ Muhammadiyah Surakarta \\ Jl. A. Yani, Mendungan \\ Pabelan, Kartasura \\ Sukoharjo, Jawa Tengah \\ nurul.hidayati@ums.ac.id
}

\author{
Eva Wahyu Indriyati \\ Jurusan Teknik Sipil \\ Fakultas Teknik \\ Universitas Jenderal Soedirman \\ Jl. Mayjen. Sungkono Km 5 \\ Kalimanah, Purbalingga \\ Jawa Tengah \\ eva.indriyati@unsoed.ac.id
}

\begin{abstract}
Driver speed that exceeds the limit is one of many factors that trigger road accidents. This study aims to analyze the differences in driver perception in choosing the speed of the vehicle. This research was conducted in two cities with characteristics assumed to have different socio-cultural aspects, namely Semarang City representing the big city and Purwokerto City as the medium city. The study uses questionnaire data distributed to respondents of vehicle users and analyzed using quantitative descriptive methods. It is known that motorists or drivers in the two cities above have the same perception related to the reason for speeding, namely travel time and punctuality to the destination. However, there are differences in perceptions on the negative effect that underlie the decision making, namely self-actualization for the release of anger and praise. Referring to several reasons in the questionnaire, the answers of drivers in Semarang lead to the poles agree, while in Purwokerto, they lead to disagreeing. Also, it was found that the driver's knowledge of speed limits can affect the choice of speed values taken. This can be seen in the high percentage of respondents who do not know the speed limit of urban roads and the high percentage of motorists who do the speeding.
\end{abstract}

Keywords: Behaviour, Violation, Accident, Traffic.

\begin{abstract}
Abstrak
Kecepatan kendaraan pengendara yang melebihi batas menjadi salah satu faktor pencetus terjadinya kecelakaan di jalan raya. Penelitian ini bertujuan untuk menganalisis perbedaan persepsi masyarakat dalam berkendara. Penelitian ini dilakukan di dua kota dengan karakteristik yang diasumsikan mempunyai sosial budaya yang berbeda, yaitu Kota Semarang merepresentasikan kota besar dan Kota Purwokerto sebagai kota sedang. Penelitian ini menggunakan data kuisioner yang dibagikan kepada responden pengguna kendaraan, dan dianalisis dengan metode deskriptif kuantitatif. Berdasarkan hasil analisis dapat diketahui bahwa pengendara di kedua kota di atas mempunyai persepsi yang sama terkait dengan alasan berkendara melebihi kecepatan, yaitu waktu tempuh dan ketepatan waktu sampai di tujuan. Meskipun demikian, ada perbedaan persepsi pada pengaruh negatif yang mendasari pengambilan keputusan tersebut, yaitu aktualisasi diri untuk pelampiasan marah dan mendapat pujian. Berdasarkan beberapa alasan yang ada di kuisioner, jawaban pengendara dan pengemudi di Kota Semarang mengarah pada kutub setuju, sedangkan di Kota Purwokerto mengarah tidak setuju. Selain itu diketahui bahwa pengetahuan pengendara tentang batas kecepatan dapat mempengaruhi pemilihan nilai kecepatan yang diambil. Hal ini terlihat pada tingginya persentase responden yang tidak mengetahui batas kecepatan jalan perkotaan dan tingginya persentase pengendara yang mengemudi di atas batas kecepatan.
\end{abstract}

Kata kunci: Perilaku, Pelanggaran, Kecelakaan, Lalu Lintas 


\section{PENDAHULUAN}

Kecelakaan lalu lintas (lakalantas) menjadi hal yang sangat perlu untuk diperhatikan di kawasan perkotaan Indonesia, termasuk di Wilayah Polda Jawa Tengah. Hal ini berkaitan dengan jumlah kejadian lakalantas yang cukup tinggi yang mencapai 4876 kejadian, dengan 1062 korban meninggal, 54 luka berat, dan 5735 luka ringan (Korlantas, 2018). Kecepatan ('cepatan') merupakan salah satu faktor yang berperan sebagai penyebab terjadinya kecelakaan. Kecepatan dalam hal ini terkait dengan perilaku berkendara yang pada dasarnya bagian dari faktor manusia.

Menurut Mohanty dan Gupta (2015) dan Javadi (2015) kecelakaan dapat terjadi karena berbagai faktor meskipun demikian penyebab yang paling banyak adalah faktor manusia atau pengendara kendaraan. Pernyataan ini didukung dari hasil penelitian terbaru oleh Hidayati dan Erwanda (2018) yang mengidentifikasikan bahwa berdasarkan data Satlantas Polresta Surakarta diketahui $87,98 \%$ pelanggaran terkait dengan perilaku pengendara, sedangkan sisanya $12,02 \%$ terkait kendaraan. Tak jauh berbeda, berdasarkan data Korlantas Polri, Siregar (2018) menyebutkan bahwa 93\% lakalantas disebabkan oleh manusia, $4 \%$ terkait unsur kendaraan, dan 3\% berhubungan dengan jalan dan lingkungan. Faktor manusia yang bisa menjadi penyebab lakalantas diantaranya adalah: mengoperasikan handphone saat berkendara, tidak mematuhi rambu lalulintas, melanggar batas kecepatan, dan lain-lain. Faktor ini berkaitan dengan munculnya pelanggaran lalu lintas di jalan raya yang dilakukan oleh pengendara kendaraan.

Perencanaan alinemen horisontal pada desain geometrik jalan raya mempertimbangkan kecepatan tertentu baik untuk bagian jalan yang lurus maupun yang menikung. Batas kecepatan yang dapat digunakan oleh pengendara dalam kondisi aman sesuai kecepatan rencana berbeda-beda tergantung pada tipe jalannya. Semakin jauh kecepatan pengendara melebihi batas kecepatan yang diijinkan maka dapat menyebabkan kecelakaan dengan tingkat fatalitas tinggi (Finch, 1994, Peden dkk, 2004). Kecepatan adalah wujud perilaku pengendara atau pengemudi di jalan raya. Perilaku tersebut merupakan hasil dari pengetahuan, informasi, dan pengalaman yang dimiliki oleh pengendara atau pengemudi. Ada kemungkinan latar belakang, alasan, dan motif tertentu yang menyebabkan pengendara menentukan angka kecepatan tertentu ketika mengendarai atau mengemudikan kendaraan di jalan raya.

Oleh karena itu penelitian ini dilakukan untuk mengetahui perilaku pengendara atau pengemudi kendaraan terkait dengan kecepatan di wilayah Kepolisian Daerah Jawa Tengah yang meliputi latar belakang, alasan, dan motif pengambilan angka kecepatan berkendara. Dua kota dengan karakteristik yang berbeda dipilih sebagai lokasi studi, yaitu Kota Semarang mewakili kota besar dan Kota Purwokerto mewakili kota sedang. Hal ini dilakukan untuk melihat apakah kondisi kota memberikan kontribusi terhadap perilaku berkendara pengguna jalan. Selain itu, kedua kota tersebut secara geografis terletak pada lokasi yang berbeda yang secara sosiologis akan berpengaruh terhadap karakteristik penduduknya. Mengikuti klasifikasi perkotaan Indonesia dari Nas (1986), Semarang merupakan kota pesisir (coastal city), sedangkan Purwokerto merupakan kota pedalaman (inland city). Kedua kota yang diambil mempunyai karakteristik yang berbeda karena posisi geografis sehingga memungkinkan coastal cities cenderung untuk lebih terbuka, dinamis, dan heterogen dibandingkan dengan inland cities. 


\section{METODE PENELITIAN}

Penelitian ini menggunakan data primer berupa data kuisioner perilaku berlalu lintas yang dibagikan pada responden di wilayah Kepolisian Daerah Jawa Tengah. Pengambilan data dilakukan secara online menggunakan form google.doc yang dibagikan melalui media komunikasi yang ada (e-mail, WhatsApp). Jumlah responden yang diharapkan adalah 300 orang, meskipun demikian jumlah tersebut tidak terpenuhi. Hal ini dikarenakan tidak mudah untuk mendapatkan balasan atau jawaban dari responden. Penelitian ini juga menggunakan data sekunder terkait data kecelakaan lalu lintas yang bersumber dari Korlantas Polri.

Model kuisioner yang digunakan dalam penelitian ini adalah kombinasi kuisioner tertutup dan terbuka dengan responden diberikan pilihan-pilihan tertentu terhadap suatu pertanyaan yang diajukan. Secara garis besar, pertanyaan dikelompokkan untuk:

1. menggali karakteristik responden yang dilihat dari jenis kelamin, penggunaan moda, lama atau tidaknya mengemudi atau berkendara, dan

2. mengidentifikasi latar belakang, alasan, dan motif pengambilan angka kecepatan dalam berkendara yang berpengaruh positif maupun negatif. Analisis dilakukan dengan metode deskriptif kuantitatif untuk memperoleh dan memberikan gambaran mengenai kondisi yang ada di kedua kota yang menjadi objek studi.

\section{HASIL DAN PEMBAHASAN}

Selain kondisi fisik pengendara, kendaraan, jalan, dan lingkungan, perilaku pengendara dalam berlalu lintas merupakan salah satu faktor penyebab terjadinya kecelakaan lalu lintas. Berdasarkan hasil survei perilaku berkendara di Kota Purwokerto dan Kota Semarang dapat diidentifikasi karakteristik pengguna, alasan serta latar belakang pemilihan kecepatan yang akan diuraikan dalam bagian ini. Bagian pertama akan membahas tentang karakteristik pengguna yang meliputi: jenis kelamin, usia, dan kepemilikan Surat Ijin Mengemudi (SIM). Bagian kedua akan menganalisis data responden tentang latar belakang alasan pengambilan angka kecepatan tertentu yang meliputi: 1) kesadaran dan pengetahuan tentang mengemudi melewati batas kecepatan, dan 2) pengambilan nilai kecepatan dan latar belakang berkendara melebihi batas kecepatan. Seperti sudah disampaikan sebelumnya, perilaku di jalan raya merupakan ekspresi dari pengetahuan dan pengalaman serta sikap diri dari pengemudi. Identifikasi bagaimana kesadaran para pengemudi tentang konsekuensi ketika mengambil kecepatan yang tinggi saat berkendara perlu dilakukan. Bagian akhir dari bahasan ini adalah membandingkan bagaimana alasan pengambilan kecepatan tinggi tersebut di dua wilayah studi.

\section{KARAKTERISTIK RESPONDEN}

\section{Jenis Kelamin dan Usia}

Berdasarkan hasil pengolahan data dapat diketahui bahwa responden mempunyai usia yang beragam. Keberagaman ini menggambarkan sebaran sikap dan motivasi yang merata di semua tingkatan usia. Kisaran usia antara terendah dan tertinggi yang cukup jauh diharapkan akan menghasilkan sebaran data yang mampu merepresentasikan kondisi riil pengendara. Tabel 1 menampilkan sebaran usia responden di kedua kota studi berdasarkan klasifikasi usia dari Departemen Kesehatan RI. 
Tabel 1. Karakteristik responden berdasarkan sebaran usia

\begin{tabular}{|c|c|c|c|}
\hline \multirow[b]{2}{*}{ Usia } & \multicolumn{2}{|c|}{ Purwokerto } & Semarang \\
\hline & $\begin{array}{c}\text { Mengemudi } \geq 5 \text { kali } \\
\text { dalam seminggu }\end{array}$ & $\begin{array}{c}\text { Mengemudi < } 5 \text { kali } \\
\text { dalam seminggu }\end{array}$ & $\begin{array}{l}\text { Mengemudi } \geq 5 \text { kali } \\
\text { dalam seminggu }\end{array}$ \\
\hline Remaja akhir & $45,28 \%$ & $36,36 \%$ & $29,41 \%$ \\
\hline Dewasa awal & $22,64 \%$ & $36,36 \%$ & $23,53 \%$ \\
\hline Dewasa akhir & $26,42 \%$ & $9,09 \%$ & $35,29 \%$ \\
\hline Lansia awal & $5,66 \%$ & $18,18 \%$ & $5,88 \%$ \\
\hline Lansia akhir & - & & $5,88 \%$ \\
\hline Keterangan: & $\begin{array}{l}\text { naja akhir: usia } 17 \text { s. } \\
\text { vasa awal: } 26 \text { s.d. } 35 \\
\text { vasa akhir: } 36 \text { s.d. } 45\end{array}$ & $\begin{array}{l}25 \text { tahun } \\
\text { hun } \\
\text { hun }\end{array}$ & $\begin{array}{l}\text { Lansia awal: } 46 \text { s.d. } 5 \\
\text { Lansia akhir: } 56 \text { s.d. } 6\end{array}$ \\
\hline \multicolumn{4}{|c|}{$\begin{array}{l}\text { Selain usia, berdasarkan analisis dapat diketahui responden dari kedua ko } \\
\text { distribusi berbeda tiap jenis kelamin seperti terlihat pada Gambar } 1 . \\
\text { Purwokerto lebih banyak laki-laki dari perempuan, sebaliknya responder } \\
\text { lebih banyak perempuan. }\end{array}$} \\
\hline & \multicolumn{2}{|c|}{$68.75 \%$} & $61.90 \%$ \\
\hline & $31.25 \%$ & & $38.10 \%$ \\
\hline & \multicolumn{3}{|c|}{ Purwokerto $\square$ Perempuan $\quad$ Laki-laki Semarang } \\
\hline
\end{tabular}

Gambar 1. Persentase jenis kelamin responden

\section{Kepemilikan Surat Izin Mengemudi (SIM)}

Kepemilikan SIM seharusnya dapat menjadi salah satu parameter untuk mengindikasikan pengetahuan pengemudi tentang aturan lalu lintas. Pengetahuan ini kemudian akan berpengaruh terhadap pengambilan keputusan dalam berkendara yang terwujud dari perilaku berlalu lintas di jalan. Berdasarkan klasifikasi wilayah (Jawa Tengah, Kota Purwokerto, dan Kota Semarang) dapat diketahui bahwa lokasi studi memiliki tingkat kepemilikan SIM yang sangat tinggi $(>90 \%)$. Hanya sekitar $10 \%$ responden yang tidak memiliki SIM dengan alasan yang tidak diketahui. Distribusi kepemilikan SIM disajikan dalam Tabel 2.

Tabel 2. Distribusi kepemilikan SIM

\begin{tabular}{cccc}
\hline \multirow{2}{*}{ Memiliki SIM } & \multicolumn{3}{c}{ Persentase Kepemilikan SIM tiap Lokasi } \\
\cline { 2 - 4 } & Purwokerto & Semarang & Jateng \\
\hline Ya & 92,19 & 100 & 94,12 \\
Tidak & 7,81 & 0 & 5,88 \\
\hline
\end{tabular}




\section{Kesadaran dan Pengetahuan Pengendara Tentang Batas Kecepatan}

Bagian ini membahas kesadaran dan pengetahuan pengendara terhadap bahaya ngebut dan ketentuan batas-batas kecepatan yang dianjurkan. Kedua hal tersebut seharusnya menjadi dasar bagi pengendara untuk berperilaku yang tepat dalam berlalu lintas, khususnya dalam mengambil besaran kecepatan.

\section{Kesadaran tentang perilaku ngebut}

Responden pengendara dalam penelitian ini diklasifikasikan menjadi dua jenis, yaitu yang berkendara kurang dari 5 kali dan yang minimal 5 kali dalam 1 minggu terakhir. Kelompok pertama diasumsikan hanya berkendara sesekali, sedangkan kelompok kedua diasumsikan sebagai pengendara rutin. Kesadaran tentang bahaya ngebut sebagai pemicu terjadinya kecelakaan ternyata relatif tinggi bagi responden di wilayah studi. Persentase jawaban dari kedua wilayah disajikan dalam Tabel 3. Jawaban yang diberikan responden pada semua kondisi ( $<5$ tahun dan $\geq 5$ tahun) di kedua kota lebih dari 50\% mengarah pada kutub 'mungkin' (mungkin dan sangat mungkin). Walaupun demikian, untuk Kota Semarang persentase respon ke arah kutub 'tidak mungkin' relatif besar $(41,17 \%)$ pada kelompok responden yang mengemudi $\geq 5$ kali dalam seminggu. Hal ini dapat diasumsikan bahwa sebanyak $41,17 \%$ pengendara di Kota Semarang memberikan persepsi yang tidak mungkin terhadap terjadinya kecelakaan karena perilaku ngebut di jalan.

Tabel 3. Persentase jawaban responden akan kemungkinan kecelakaan lalu lintas

\begin{tabular}{ccccc}
\hline & \multicolumn{2}{c}{ Perilaku Ngebut Meningkatkan Kemungkinan Anda Mengalami Kecelakaan } \\
\cline { 2 - 5 } Sikap & \multicolumn{2}{c}{ Purwokerto } & Semarang \\
\cline { 2 - 5 } & $\begin{array}{c}\text { Mengemudi } \begin{array}{c}\text { kali dalam } \\
\text { seminggu }\end{array} \\
\text { Sangat tidak mungkin }\end{array}$ & $\begin{array}{c}\text { Mengemudi } \\
\text { kali dalam } \\
\text { seminggu }\end{array}$ & $\begin{array}{c}\text { Mengemudi } \geq \mathbf{5} \\
\text { kali dalam } \\
\text { seminggu }\end{array}$ & $\begin{array}{c}\text { Mengemudi }<5 \\
\text { kali dalam } \\
\text { seminggu }\end{array}$ \\
\hline Tidak mungkin & $3,77 \%$ & $9,09 \%$ & $11,76 \%$ & - \\
\hline Mungkin & $7,55 \%$ & $9,09 \%$ & $29,41 \%$ & $25,00 \%$ \\
\hline Sangat mungkin & $71,70 \%$ & $54,55 \%$ & $29,41 \%$ & - \\
\hline
\end{tabular}

\section{Pengetahuan batas-batas kecepatan}

Pengambilan kecepatan tertinggi, seperti disebutkan sebelumnya, diasumsikan berkorelasi dengan pengetahuan yang dimiliki, sikap diri, dan dorongan dari lingkungan. Pengetahuan diartikan sebagai informasi yang dimiliki oleh pengemudi/pengendara mengenai apa yang seharusnya mereka lakukan dalam mengemudi atau mengendara kendaraannya. Pengetahuan dalam riset ini diwakili oleh pertanyaan tentang batas-batas kecepatan untuk tiga tipe jalan yang berbeda menurut pengetahuan pengendara. Tabel 4 menyajikan persentase jawaban responden sesuai dengan domisili tentang batas kecepatan di tiga tipe jalan berbeda. 
Tabel 4. Pengetahuan responden tentang batas kecepatan pada tipe jalan yang berbeda

\begin{tabular}{|c|c|c|c|c|}
\hline \multirow{2}{*}{$\begin{array}{c}\text { Kecepatan } \\
\text { Teringgi } \\
\text { (km/jam) }\end{array}$} & \multicolumn{2}{|c|}{ Purwokerto } & \multicolumn{2}{|c|}{ Semarang } \\
\hline & $\begin{array}{l}\text { Mengemudi } \geq 5 \text { kali } \\
\text { dalam seminggu }\end{array}$ & $\begin{array}{c}\text { Mengemudi < } 5 \text { kali } \\
\text { dalam seminggu }\end{array}$ & $\begin{array}{l}\text { Mengemudi } \geq 5 \text { kali } \\
\text { dalam seminggu }\end{array}$ & $\begin{array}{c}\text { Mengemudi < } 5 \text { kali } \\
\text { dalam seminggu }\end{array}$ \\
\hline \multicolumn{5}{|c|}{ Jalan Perkotaan } \\
\hline$\leq 50$ & $11,54 \%$ & $27,27 \%$ & $18,75 \%$ & $25,00 \%$ \\
\hline$>50$ & $88,46 \%$ & $72,73 \%$ & $81,25 \%$ & $75,00 \%$ \\
\hline \multicolumn{5}{|c|}{ Jalan Antar Kota } \\
\hline$\leq 80$ & $98,08 \%$ & $100,00 \%$ & $93,75 \%$ & $100,00 \%$ \\
\hline$>80$ & $1,92 \%$ & - & $6,25 \%$ & - \\
\hline \multicolumn{5}{|c|}{ Jalan Bebas Hambatan (Jalan Tol) } \\
\hline$<60$ & - & - & - & - \\
\hline $60-100$ & $80,77 \%$ & $90,91 \%$ & $93,75 \%$ & $75,00 \%$ \\
\hline$>100$ & $19,23 \%$ & $9,09 \%$ & $6,25 \%$ & $25,00 \%$ \\
\hline
\end{tabular}

Kecepatan yang diizinkan, menurut Peraturan Pemerintah RI Nomor 79 tahun 2013 tentang Jaringan Lalu Lintas dan Angkutan Jalan (Menkumham, 2013) pada tipe-tipe jalan yang berbeda adalah sebagai berikut:

a. Jalan perkotaan: batas kecepatan maksimal $50 \mathrm{~km} / \mathrm{jam}$

b. Jalan antar kota: batas kecepatan maksimal $80 \mathrm{~km} / \mathrm{jam}$

c. Jalan bebas hambatan: batas kecepatan antara $60 \mathrm{~km} / \mathrm{jam}$ sampai dengan $100 \mathrm{~km} / \mathrm{jam}$

Didasarkan pada standar batas kecepatan pada masing-masing jalan sesuai peraturan yang berlaku maka pengetahuan pengendara di kedua kota mempunyai bias paling besar pada batas kecepatan pada jalan perkotaan. Lebih dari $72 \%$ responden menyebutkan bahwa batas tertinggi kecepatan di jalan perkotaan $>80 \mathrm{~km} / \mathrm{jam}$. Besaran persentase ini jika dilihat dari tipe pengendaranya lebih besar pada pengendara yang rutin berkendara di jalan. Hal ini menjadi perhatian karena akan berkaitan dengan potensi kecelakaan yang terjadi di jalan perkotaan. Pada dua klasifikasi jalan yang lain, mayoritas responden sudah mempunyai pengetahuan tentang batas kecepatan yang diizinkan. Hanya pada jalan bebas hambatan untuk tipe pengendara yang tidak rutin mengendara di Kota Semarang, sebanyak $25 \%$ tidak tahu bahwa batas kecepatan tertinggi di jalan tol adalah $100 \mathrm{~km} / \mathrm{jam}$. Persentase ini lebih tinggi jika dibandingkan dengan pengendara dengan tipe pengendara rutin di Kota Purwokerto yang sebesar 19,23\% tidak mempunyai pengetahuan terhadap hal yang sama.

\section{Pengambilan Nilai Kecepatan dan Latar Belakang Berkendara Melebihi Batas Kecepatan}

Kecepatan kendaraan yang diambil oleh para pengendara dan pengemudi di kedua wilayah studi merupakan realisasi dari perilaku, pengetahuan, dan pengalaman yang dimiliki. Kecepatan maksimal yang diambil para pengendara/pengemudi di berbagai jenis jalan merepresentasikan realitas keputusan pengambilan kecepatan mereka di jalan. Berdasarkan data yang diperoleh, kecepatan yang diambil disajikan dalam Tabel 5. 
Tabel 5. Kecepatan pengendara/pengemudi pada tipe jalan yang berbeda di dua kota studi

\begin{tabular}{|c|c|c|c|c|}
\hline \multirow{2}{*}{$\begin{array}{c}\text { Kecepatan } \\
\text { Teringgi } \\
\text { (km/jam) }\end{array}$} & \multicolumn{2}{|c|}{ Purwokerto } & \multicolumn{2}{|c|}{ Semarang } \\
\hline & $\begin{array}{l}\text { Mengemudi } \geq 5 \text { kali } \\
\text { dalam seminggu }\end{array}$ & $\begin{array}{c}\text { Mengemudi < } 5 \text { kali } \\
\text { dalam seminggu }\end{array}$ & $\begin{array}{l}\text { Mengemudi } \geq 5 \text { kali } \\
\text { dalam seminggu }\end{array}$ & $\begin{array}{c}\text { Mengemudi < } 5 \text { kali } \\
\text { dalam seminggu }\end{array}$ \\
\hline \multicolumn{5}{|c|}{ Jalan Perkotaan } \\
\hline$\leq 50$ & $15,09 \%$ & $27,27 \%$ & $11,76 \%$ & $25,00 \%$ \\
\hline$>50$ & $84,91 \%$ & $72,73 \%$ & $88,24 \%$ & $75,00 \%$ \\
\hline \multicolumn{5}{|c|}{ Jalan Antar Kota } \\
\hline$\leq 80$ & $83,02 \%$ & $100,00 \%$ & $82,35 \%$ & $100,00 \%$ \\
\hline$>80$ & $16,98 \%$ & - & $17,65 \%$ & - \\
\hline \multicolumn{5}{|c|}{ Jalan Bebas Hambatan (Jalan Tol) } \\
\hline$<60$ & $2,33 \%$ & $9,09 \%$ & - & - \\
\hline $60-100$ & $72,09 \%$ & $81,82 \%$ & $76,92 \%$ & $75,00 \%$ \\
\hline$>100$ & $25,58 \%$ & $9,09 \%$ & $23,08 \%$ & $25,00 \%$ \\
\hline
\end{tabular}

Persentase terbesar pengendara yang mengemudi/mengedarai kendaraan melebihi batas kecepatan ada pada jalan perkotaan. Angka > 80\% di kedua kota studi menunjukkan mayoritas pengendara melebihi batas kecepatan. Persentase lebih tinggi terjadi pada pengemudi/pengendara yang rutin mengendara. Rutinitas yang sudah dijalankan dimungkinkan potensial untuk membuat mereka mengemudi melebihi batas kecepatan. Persentase pengendara/pengemudi yang melebihi batas kecepatan untuk dua jalan yang berbeda lainnya seperti disajikan dalam tabel menunjukkan tren yang sama. Kisaran persentase yang mendekati sama untuk kedua kota studi. Perbedaan yang ada terdapat pada tipe jalan bebas hambatan. Pengemudi berdomisili Kota Semarang yang tidak rutin mengemudi dan mengemudi melebihi batas kecepatan mempunyai persentase yang hampir sama dengan pengemudi lainnya yang merupakan pengemudi rutin. Kondisi jalan tol yang bebas hambatan dimungkinkan menjadi pendorong kondisi ini, termasuk kecepatan yang diambil oleh pengendara-pengendara lain di jalan bebas hambatan.

\section{Latar Belakang Berkendara Melebihi Batas Kecepatan}

Pengambilan kecepatan tersebut tentu saja mempunyai hal yang melatarbelakangi. Di dalam riset ini pertanyaan terkait alasan dibedakan pada pertanyaan yang bernilai positif dan pertanyaan lainnya bernilai negatif yang terkait dengan afeksi positif dan negatif. Beberapa diantaranya adalah alasan cepat sampai tujuan, agar sampai tujuan tepat waktu, memberikan kesempatan untuk uji nyali, dan mengurangi stress sebagai pertanyaan yang berafeksasi positif. Sedangkan tujuh lainnya adalah alasan-alasan serta latar belakang yang berafeksasi negative, yaitu menyalurkan hobi berkendara, menghilangkan rasa kantuk, meningkatkan konsentrasi di jalan, menunjukkan kemampuan mengemudi kepada pengemudi lain, menyalurkan rasa marah, memperoleh pujian dari orang lain, dan lolos dari kejaran Polisi

\section{Alasan agar cepat sampai tujuan}

Pemilihan suatu batas kecepatan tertentu bertendensi untuk mengarah pada kutub setuju (sebesar > 75\%) mengambil kecepatan karena alasan agar cepat sampai tujuan. 
Rekapitulasi hasil sikap yang diberikan kedua kelompok pengendara tersebut dapat dilihat dalam Tabel 6. Komparasi distribusi di kedua kota studi mengidentifikasikan bahwa walaupun seperti disebutkan sebelumnya pernyataan mengebut dilakukan dengan alasan agar cepat sampai tujuan terpolarisasi pada jawaban setuju, tetapi di Semarang untuk kelompok yang mengemudi < 5 kali dalam seminggu $25 \%$ menjawab tidak setuju. Artinya untuk kelompok ini di Semarang ada alasan lain yang mendasari keputusan untuk mengebut.

Tabel 6. Persentase responden yang beralasan agar cepat sampai tujuan

\begin{tabular}{ccccc}
\hline \multirow{2}{*}{ Sikap } & \multicolumn{3}{c}{ Ngebut Agar Lebih Cepat Sampai di Tempat Tujuan } \\
\cline { 2 - 5 } & \multicolumn{2}{c}{ Purwokerto } & \multicolumn{2}{c}{ Semarang } \\
\cline { 2 - 5 } & $\begin{array}{c}\text { Mengemudi } \geq \mathbf{5} \\
\text { kali dalam } \\
\text { seminggu }\end{array}$ & $\begin{array}{c}\text { Mengemudi }<5 \\
\text { kali dalam } \\
\text { seminggu }\end{array}$ & $\begin{array}{c}\text { Mengemudi } \geq 5 \\
\text { kali dalam } \\
\text { seminggu }\end{array}$ & $\begin{array}{c}\text { Mengemudi < 5 } \\
\text { kali dalam } \\
\text { seminggu }\end{array}$ \\
\hline Sangat tidak mungkin & $3,77 \%$ & $9,09 \%$ & $5,88 \%$ & - \\
\hline Tidak mungkin & $13,21 \%$ & $9,09 \%$ & $5,88 \%$ & $25,00 \%$ \\
\hline Mungkin & $56,60 \%$ & $72,73 \%$ & $64,71 \%$ & $25,00 \%$ \\
\hline Sangat mungkin & $26,42 \%$ & $9,09 \%$ & $23,53 \%$ & $50,00 \%$ \\
\hline
\end{tabular}

\section{Agar sampai tujuan tepat waktu}

Rasionalitas responden dengan mengambil nilai kecepatan tertentu agar sampai tujuan tepat waktu ada pada kedua klasifikasi responden. Persentase jawaban 'setuju' dan 'sangat setuju' yang besar mengindikasikan alasan yang rasionalitas dari responden. Para pengendara dan pengemudi di kedua kota memberikan jawaban yang mengkutub pada setuju dan sangat setuju. Bahkan pada kelompok pengemudi yang mengemudi $<5$ kali dalam seminggu $100 \%$ menjawab setuju. Di sini pengambilan keputusan terkait kecepatan tidak dipengaruhi oleh rutinitas penggunaan kendaraan yang juga berkaitan dengan proses interaksi yang berkesinambungan dengan rute jalan yang dilalui. Rekapitulasi hasil sikap yang diberikan bel kedua kelompok pengendara tersebut dapat dilihat dalam Tabel 7.

Tabel 7. Persentase responden yang beralasan agar sampai tujuan tepat waktu

\begin{tabular}{ccccc}
\hline \multirow{2}{*}{ Sikap } & \multicolumn{3}{c}{ Ngebut Agar Mencapai Tempat Tujuan Tepat Waktu } \\
\cline { 2 - 5 } & \multicolumn{2}{c}{ Purwokerto } & Semarang \\
\cline { 2 - 5 } & $\begin{array}{c}\text { Mengemudi } \begin{array}{c}\text { kali dalam } \\
\text { seminggu }\end{array} \\
\text { Sangat tidak mungkin }\end{array}$ & $\begin{array}{c}\text { Mengemudi } \\
\text { kali dalam } \\
\text { seminggu }\end{array}$ & $\begin{array}{c}\text { Mengemudi } \\
\text { kali dalam 5 } \\
\text { seminggu }\end{array}$ & $\begin{array}{c}\text { Mengemudi }<5 \\
\text { kali dalam } \\
\text { seminggu }\end{array}$ \\
\hline Tidak mungkin & $1,89 \%$ & $9,09 \%$ & $5,88 \%$ & - \\
\hline Mungkin & $18,87 \%$ & $18,18 \%$ & $23,53 \%$ & - \\
\hline Sangat mungkin & $54,72 \%$ & $72,73 \%$ & $47,06 \%$ & $100,00 \%$ \\
\hline
\end{tabular}

\section{Memberikan kesempatan untuk uji nyali}

Afektifitas pengendara dengan mengambil kecepatan tinggi untuk memberikan kesempatan uji nyali mengarah pada penilaian negatif. Persentase jawaban yang diberikan oleh kedua 
tipe pengendara di kedua kota menjawab sangat tidak setuju berada antara 33,96\% sampai dengan 63,64\% dan tidak setuju antara 9,09\% sampai dengan 47,06\%. Persentase sikap yang diambil untuk kedua tipe pengendara disajikan dalam Tabel 8.

Tabel 8. Persentase responden yang beralasan untuk kesempatan uji nyali

\begin{tabular}{ccccc}
\hline \multirow{2}{*}{ Sikap } & \multicolumn{2}{c}{ Negut Agar Dapat Memberikan Kesempatan Uji Nyali } \\
\cline { 2 - 5 } & \multicolumn{2}{c}{ Purwokerto } & \multicolumn{2}{c}{ Semarang } \\
\cline { 2 - 5 } & $\begin{array}{c}\text { Mengemudi } \begin{array}{c}\text { kali dalam } \\
\text { seminggu }\end{array} \\
\text { Sangat tidak mungkin }\end{array}$ & $\begin{array}{c}\text { Mengemudi } \\
\text { kali dalam } \\
\text { seminggu }\end{array}$ & $\begin{array}{c}\text { Mengemudi } \geq 5 \\
\text { kali dalam } \\
\text { seminggu }\end{array}$ & $\begin{array}{c}\text { Mengemudi }<5 \\
\text { kali dalam } \\
\text { seminggu }\end{array}$ \\
\hline Tidak mungkin & $33,96 \%$ & $63,64 \%$ & $35,29 \%$ & $50,00 \%$ \\
\hline Mungkin & $37,74 \%$ & $9,09 \%$ & $47,06 \%$ & $25,00 \%$ \\
\hline Sangat mungkin & $20,75 \%$ & $18,18 \%$ & $11,76 \%$ & - \\
\hline
\end{tabular}

\section{Mengurangi stress}

Penilaian responden terhadap pengambilan kecepatan pada nilai tertentu dengan melihat bahwa kecepatan tersebut diambil untuk mengurangi stress direspon dengan tingkat ketidaksetujuan yang besar, yaitu lebih dari 25\%. Hal ini menunjukkan bahwa ketika responden mengambil kecepatan yang tinggi cenderung tidak didasari oleh alasan untuk mengurangi stress. Walaupun demikian untuk kategori pengendara yang mengendara $<5$ kali seminggu di Kota Semarang dan sekitarnya memberikan jawaban masing-masing 25\% untuk setuju dan sangat setuju bahwa responden mengambil kecepatan tinggi sebagai cara mereka untuk mengurangi stress. Artinya proporsi jawaban ada pada posisi 50 - 50 yang mengarah pada kedua kutub jawaban. Hasil ini secara ringkas disajikan dalam Tabel 9.

Tabel 9. Persentase responden yang beralasan ngebut untuk mengurangi stress

\begin{tabular}{ccccc}
\hline & \multicolumn{4}{c}{ Ngebut Agar Mengurangi Stres } \\
\cline { 2 - 5 } Sikap & \multicolumn{2}{c}{ Purwokerto } & Semarang \\
\cline { 2 - 5 } & $\begin{array}{c}\text { Mengemudi } \begin{array}{c}\text { kali dalam } \\
\text { seminggu }\end{array} \\
\text { Sangat tidak mungkin }\end{array}$ & $\begin{array}{c}\text { Mengemudi }<5 \\
\text { kali dalam } \\
\text { seminggu }\end{array}$ & $\begin{array}{c}\text { Mengemudi } \\
\text { kali dalam } \\
\text { seminggu }\end{array}$ & $\begin{array}{c}\text { Mengemudi }<5 \\
\text { kali dalam } \\
\text { seminggu }\end{array}$ \\
\hline Tidak mungkin & $28,30 \%$ & $54,55 \%$ & $47,06 \%$ & $25,00 \%$ \\
\hline Mungkin & $49,06 \%$ & $27,27 \%$ & $35,29 \%$ & $25,00 \%$ \\
\hline Sangat mungkin & $20,75 \%$ & $18,18 \%$ & $11,76 \%$ & $25,00 \%$ \\
\hline
\end{tabular}

\section{Alasan Pengendara Mengambil Kecepatan Melebihi Batas Yang Berafeksi Negatif}

Berdasarkan hasil kompilasi jawaban responden untuk ketujuh pertanyaan berafeksasi negatif, tiga alasan menunjukkan perbedaan yang relatif signifikan di dalam distribusi persentase jawaban. Ketiga pertanyaan dan perbedaan yang terjadi di dua kota studi adalah: 
1. Mengebut dilakukan dengan alasan untuk meningkatkan konsentrasi di jalan (Tabel 9) Pengendara di Kota Purwokerto dengan klasifikasi mengemudi > 5 kali seminggu memberikan jawaban yang mengarah pada kutub setuju sebesar 58, 49\% sedangkan untuk klasifikasi yang sama pengendara di Kota Semarang kutub setuju sebesar 35, 29\%. Kelompok pengendara yang mengemudi/mengendarai < 5 kali dalam seminggu memberikan jawaban yang mengarah ke kutub tidak setuju sebesar $81,82 \%$ untuk pengendara di Kota Purwokerto dan bertolak belakang dengan pengendara di Kota Semarang yang memberikan jawaban ke arah kutub setuju sebesar $75 \%$. Beberapa hal yang potensial merupakan motivasi dari pemilihan alasan ini kemungkinan terkait dengan volume kendaraan yang lebih besar yang dimiliki oleh Kota Semarang. Pengemudi dan pengendara yang tidak rutin berkendara akan lebih memerlukan tingkat konsentrasi yang tinggi ketika berkendara melebihi kecepatan dalam situasi arus lalu lintas yang tinggi untuk menghindari terjadinya konflik lalu lintas dengan pengguna lainnya.

2. Mengebut dilakukan dengan alasan untuk menyalurkan rasa marah (Tabel 11)

Perbedaan yang terlihat dari distribusi jawaban pada pertanyaan yang diberikan terkait berkendara melebihi kecepatan dengan alasan untuk menyalurkan rasa marah terjadi pada kelompok pengendara/pengemudi yang mengemudi kurang dari 5 kali seminggu. Pengendara di Kota Purwokerto memberikan jawaban yang 100\% mengarah pada kutub tidak setuju, sedangkan pengendara di Kota Semarang memberikan jawaban yang mengarah pada kedua kutub secara seimbang (50\%-50\%). Dari sisi psikologi, perasaan marah merupakan reaksi normal sebagai respon atas sesuatu yang salah dan mengisyaratkan tubuh untuk memperbaiki keadaan tersebut (Bhave and Saini, 2002). Untuk menghentikan marah diperlukan energi untuk melakukan aksi sehingga energi marah tersebut dapat menghilang. Dalam hal ini ekspresi marah dapat memberikan dampak baik positif maupun negatif bagi orang lain. Dengan penyaluran marah melalui pengambilan kecepatan yang melebihi batas kecepatan pada saat mengemudi, pengendara menyalurkan energi pada tubuhnya dengan cara yang bisa membahayakan dirinya maupun orang lain. Jika marah tersebut terkait dengan kepentingan diri sendiri, maka hal ini akan sejalan dengan teori karakteristik masyarakat perkotaan yang cenderung untuk bersifat individualistik yang berkaitan erat dengan persaingan dalam segala hal (Jamaludin, 2015).

3. Mengebut dilakukan dengan alasan untuk memperoleh pujian dari orang lain (Tabel 12)

Pada dasarnya jawaban yang diberikan terhadap poin pertanyaan ini mengarah pada kutub yang sama, yaitu kutub tidak setuju. Tetapi pada kelompok pengendara/pengemudi yang tidak rutin mengendara di Kota Semarang terdapat proporsi jawaban setuju sebesar 25\%. Artinya terdapat pengendara yang mempunyai alasan untuk mendapat pujian dari orang lain ketika mereka mengendara melebihi kecepatan. Dalam hal ini, ada unsur aktualisasi diri yang ingin ditunjukkan oleh pengendara tersebut.

Rekapitulasi hasil kuisioner masing-masing untuk ketujuh (7) pertanyaan yang berafeksasi negatif disajikan pada Tabel 10 sampai Tabel 16. 
Tabel 10. Persentase responden yang beralasan menyalurkan hobi berkendara

\begin{tabular}{ccccc}
\hline \multirow{2}{*}{ Sikap } & \multicolumn{3}{c}{ Ngebut Agar Menyalurkan Hoby Berkendara } \\
\cline { 2 - 5 } & \multicolumn{2}{c}{ Purwokerto } & \multicolumn{2}{c}{ Semarang } \\
\cline { 2 - 5 } & $\begin{array}{c}\text { Mengemudi } \geq \mathbf{5} \\
\text { kali dalam } \\
\text { seminggu }\end{array}$ & $\begin{array}{c}\text { Mengemudi }<5 \\
\text { kali dalam } \\
\text { seminggu }\end{array}$ & $\begin{array}{c}\text { Mengemudi } \geq 5 \\
\text { kali dalam } \\
\text { seminggu }\end{array}$ & $\begin{array}{c}\text { Mengemudi < 5 } \\
\text { kali dalam } \\
\text { seminggu }\end{array}$ \\
\hline Sangat tidak mungkin & $16,98 \%$ & $54,55 \%$ & $41,18 \%$ & - \\
\hline Tidak mungkin & $52,83 \%$ & $27,27 \%$ & $29,41 \%$ & $50,00 \%$ \\
\hline Mungkin & $24,53 \%$ & - & $17,65 \%$ & $25,00 \%$ \\
\hline Sangat mungkin & $5,66 \%$ & $18,18 \%$ & $11,76 \%$ & $25,00 \%$ \\
\hline
\end{tabular}

Tabel 11. Persentase responden yang beralasan untuk menghilangkan rasa kantuk

\begin{tabular}{ccccc}
\hline \multirow{2}{*}{ Sikap } & \multicolumn{3}{c}{ Ngebut Agar Menghilangkan Rasa Mengantuk } \\
\cline { 2 - 5 } & \multicolumn{2}{c}{ Purwokerto } & \multicolumn{2}{c}{ Semarang } \\
\cline { 2 - 5 } & $\begin{array}{c}\text { Mengemudi } \geq \mathbf{5} \\
\text { kali dalam } \\
\text { seminggu }\end{array}$ & $\begin{array}{c}\text { Mengemudi }<5 \\
\text { kali dalam } \\
\text { seminggu }\end{array}$ & $\begin{array}{c}\text { Mengemudi } \geq 5 \\
\text { kali dalam } \\
\text { seminggu }\end{array}$ & $\begin{array}{c}\text { Mengemudi < 5 } \\
\text { kali dalam } \\
\text { seminggu }\end{array}$ \\
\hline Sangat tidak mungkin & $16,98 \%$ & $54,55 \%$ & $23,53 \%$ & $50,00 \%$ \\
\hline Tidak mungkin & $33,96 \%$ & $18,18 \%$ & $52,94 \%$ & - \\
\hline Mungkin & $41,51 \%$ & $27,27 \%$ & $23,53 \%$ & $25,00 \%$ \\
\hline Sangat mungkin & $7,55 \%$ & - & - & $25,00 \%$ \\
\hline
\end{tabular}

Tabel 12. Persentase responden yang beralasan untuk meningkatkan konsentrasi di jalan

\begin{tabular}{ccccc}
\hline \multirow{2}{*}{ Sikap } & \multicolumn{3}{c}{ Ngebut Agar Meningkatkan Konsentrasi di Jalan } \\
\cline { 2 - 5 } & \multicolumn{2}{c}{ Purwokerto } & \multicolumn{2}{c}{ Semarang } \\
\cline { 2 - 5 } & $\begin{array}{c}\text { Mengemudi } \geq \mathbf{5} \\
\text { kali dalam } \\
\text { seminggu }\end{array}$ & $\begin{array}{c}\text { Mengemudi }<5 \\
\text { kali dalam } \\
\text { seminggu }\end{array}$ & $\begin{array}{c}\text { Mengemudi } \geq 5 \\
\text { kali dalam } \\
\text { seminggu }\end{array}$ & $\begin{array}{c}\text { Mengemudi < 5 } \\
\text { kali dalam } \\
\text { seminggu }\end{array}$ \\
\hline Sangat tidak mungkin & $11,32 \%$ & $54,55 \%$ & $29,41 \%$ & $25,00 \%$ \\
\hline Tidak mungkin & $30,19 \%$ & $27,27 \%$ & $35,29 \%$ & - \\
\hline Mungkin & $49,06 \%$ & $18,18 \%$ & $29,41 \%$ & $75,00 \%$ \\
\hline Sangat mungkin & $9,43 \%$ & - & $5,88 \%$ & - \\
\hline
\end{tabular}


Tabel 13. Persentase responden yang beralasan untuk menunjukkan kemampuan mengemudi kepada pengemudi lain

\begin{tabular}{|c|c|c|c|c|}
\hline \multirow{3}{*}{ Sikap } & \multicolumn{4}{|c|}{$\begin{array}{c}\text { Ngebut Agar Menunjukkan Kemampuan Mengemudi Kepada Pengemudi } \\
\text { Lain }\end{array}$} \\
\hline & \multicolumn{2}{|c|}{ Purwokerto } & \multicolumn{2}{|c|}{ Semarang } \\
\hline & $\begin{array}{c}\text { Mengemudi } \geq 5 \\
\text { kali dalam } \\
\text { seminggu }\end{array}$ & $\begin{array}{c}\text { Mengemudi < } 5 \\
\text { kali dalam } \\
\text { seminggu }\end{array}$ & $\begin{array}{c}\text { Mengemudi } \geq 5 \\
\text { kali dalam } \\
\text { seminggu }\end{array}$ & $\begin{array}{c}\text { Mengemudi < } 5 \\
\text { kali dalam } \\
\text { seminggu }\end{array}$ \\
\hline Sangat tidak mungkin & $39,62 \%$ & $54,55 \%$ & $41,18 \%$ & $50,00 \%$ \\
\hline Tidak mungkin & $43,40 \%$ & $27,27 \%$ & $47,06 \%$ & - \\
\hline Mungkin & $15,09 \%$ & $18,18 \%$ & $5,88 \%$ & $25,00 \%$ \\
\hline Sangat mungkin & $1,89 \%$ & - & $5,88 \%$ & $25,00 \%$ \\
\hline
\end{tabular}

Tabel 14. Persentase responden yang beralasan untuk menyalurkan rasa marah

\begin{tabular}{ccccc}
\hline \multirow{2}{*}{ Sikap } & \multicolumn{4}{c}{ Ngebut Agar Menyalurkan Rasa Marah } \\
\cline { 2 - 5 } & \multicolumn{2}{c}{ Purwokerto } & \multicolumn{2}{c}{ Semarang } \\
\cline { 2 - 5 } & $\begin{array}{c}\text { Mengemudi } \geq 5 \\
\text { kali dalam } \\
\text { seminggu }\end{array}$ & $\begin{array}{c}\text { Mengemudi }<5 \\
\text { kali dalam } \\
\text { seminggu }\end{array}$ & $\begin{array}{c}\text { Mengemudi } \geq 5 \\
\text { kali dalam } \\
\text { seminggu }\end{array}$ & $\begin{array}{c}\text { Mengemudi < 5 } \\
\text { kali dalam } \\
\text { seminggu }\end{array}$ \\
\hline Sangat tidak mungkin & $33,96 \%$ & $54,55 \%$ & $35,29 \%$ & $25,00 \%$ \\
\hline Tidak mungkin & $39,62 \%$ & $45,45 \%$ & $35,29 \%$ & $25,00 \%$ \\
\hline Mungkin & $20,75 \%$ & - & $23,53 \%$ & $25,00 \%$ \\
\hline Sangat mungkin & $5,66 \%$ & - & $5,88 \%$ & $25,00 \%$ \\
\hline
\end{tabular}

Tabel 15. persentase responden yang beralasan untuk memperoleh pujian dari orang di sekitar

\begin{tabular}{ccccc}
\hline \multirow{2}{*}{ Sikap } & \multicolumn{3}{c}{ Ngebut Agar Memperoleh Pujian Dari Orang di Sekitar } \\
\cline { 2 - 5 } & \multicolumn{2}{c}{ Purwokerto } & Semarang \\
\cline { 2 - 5 } & $\begin{array}{c}\text { Mengemudi } \begin{array}{c}\text { kali dalam } \\
\text { seminggu }\end{array} \\
\text { Sangat tidak mungkin }\end{array}$ & $\begin{array}{c}\text { Mengemudi } \\
\text { kali dalam } \\
\text { seminggu }\end{array}$ & $\begin{array}{c}\text { Mengemudi } \\
\text { kali dalam 5 } \\
\text { seminggu }\end{array}$ & $\begin{array}{c}\text { Mengemudi } \\
\text { kali dalam } \\
\text { seminggu }\end{array}$ \\
\hline Tidak mungkin & $45,28 \%$ & $63,64 \%$ & $52,94 \%$ & $50,00 \%$ \\
\hline Mungkin & $49,06 \%$ & $36,36 \%$ & $47,06 \%$ & $25,00 \%$ \\
\hline Sangat mungkin & $3,77 \%$ & - & - & $25,00 \%$ \\
\hline
\end{tabular}


Tabel 16. Persentase responden yang beralasan untuk lolos dari tangkapan polisi

\begin{tabular}{ccccc}
\hline \multirow{2}{*}{ Sikap } & \multicolumn{4}{c}{ Ngebut Agar Lolos Dari Tangkapan Polisi } \\
\cline { 2 - 5 } & \multicolumn{2}{c}{ Purwokerto } & \multicolumn{2}{c}{ Semarang } \\
\cline { 2 - 5 } & $\begin{array}{c}\text { Mengemudi } \geq \mathbf{5} \\
\text { kali dalam } \\
\text { seminggu }\end{array}$ & $\begin{array}{c}\text { Mengemudi }<5 \\
\text { kali dalam } \\
\text { seminggu }\end{array}$ & $\begin{array}{c}\text { Mengemudi } \geq 5 \\
\text { kali dalam } \\
\text { seminggu }\end{array}$ & $\begin{array}{c}\text { Mengemudi < 5 } \\
\text { kali dalam } \\
\text { seminggu }\end{array}$ \\
\hline Sangat tidak mungkin & $50,94 \%$ & $72,73 \%$ & $58,82 \%$ & $50,00 \%$ \\
\hline Tidak mungkin & $37,74 \%$ & $18,18 \%$ & $29,41 \%$ & $25,00 \%$ \\
\hline Mungkin & $3,77 \%$ & $9,09 \%$ & $5,88 \%$ & - \\
\hline Sangat mungkin & $7,55 \%$ & - & $5,88 \%$ & $25,00 \%$ \\
\hline
\end{tabular}

\section{KESIMPULAN}

Pengambilan suatu angka kecepatan pada saat mengemudi atau mengendara mempengaruhi potensi terjadinya kecelakaan di jalan raya. Sebagai bagian dari perilaku berkendara, kecepatan yang diambil merupakan perwujudan sikap, pengetahuan, dan informasi yang diketahui oleh seorang pengendara. Riset ini bertujuan untuk mengidentifikasi kemungkinan adanya perbedaan perilaku pengambilan angka kecepatan tertentu, terutama yang melebihi batas kecepatan, pada dua kota dengan karakteristik yang berbeda. Data jawaban responden memberikan temuan-temuan sebagai berikut:

1. Pengendara di kedua wilayah studi mempunyai persepsi yang sama terkait dengan alasan waktu tempuh dan ketepatan waktu sampai di tujuan terdapat pada jawaban dari responden di kota-kota studi pada semua klasifikasi pengendara. Artinya kedua hal ini menjadi motif penting yang menentukan keputusan berkendara dengan melebihi kecepatan pada dua tipe kota yang berbeda.

2. Dilihat dari pengetahuan dan perilaku di jalan, terjadi korelasi yang positif diantara keduanya. Semakin besar persentase pengendara yang tidak tahu batas tertinggi kecepatan di suatu tipe jalan semakin besar pula persentase pengendara yang berperilaku berkendara melebihi batas kecepatan. Dalam kondisi ini, diidentifikasi bahwa persentase perilaku pengendara di Kota Semarang relatif lebih memperhatikan pengetahuan yang mereka miliki dengan implementasinya di jalan. Hal ini dapat dilihat dari perbandingan persentase pengendara yang mengetahui batas kecepatan tertinggi dan persentase yang melanggar.

3. Pada dasarnya konsepsi dan perilaku pengendara di kedua kota studi menunjukkan pola yang relatif sama. Asumsi bahwa karakteristik kota memberikan pengaruh terhadap pengambilan keputusan untuk berkendara melebihi kecepatan terjadi pada alasan 'mengemudi melebihi batas kecepatan karena didasari pelampiasan marah' di Kota Semarang, yang adalah kota besar dengan karakteristik sebagai coastal city, pada pengemudi yang tidak rutin berkendara. Selain itu berdasarkan hasil kuesioner, sebanyak 25\% pengendara di Kota Semarang mempunyai latar belakang untuk aktualisasi diri untuk mendapat pujian ketika mengemudi melebihi batas kecepatan.

Berdasarkan hasil penelitian ini, terkait dengan peningkatan keselamatan berlalu lintas, rekomendasi yang diberikan adalah diperlukannya pendekatan tentang pengetahuan berlalu lintas yang lebih baik dengan menekankan pada sikap dan pengaturan emosi selama 
berkendara. Metode dan model yang bisa diterapkan dapat menjadi materi untuk dilakukannya penelitian lanjutan.

\section{UCAPAN TERIMA KASIH}

Ucapan terima kasih disampaikan kepada Kepolisian Republik Indonesia melalui DIPA Korlantas Polri Tahun Anggaran 2019 yang telah memberikan Hibah Penelitian Traffic Accident Research Center (TARC) kepada penulis. Selain itu ucapan terima kasih juga disampaikan kepada Korlantas Polri beserta jajarannya, khususnya Polda Jateng yang telah membantu dalam menyediakan data maupun mengawal pengambilan data primer.

\section{DAFTAR PUSTAKA}

Bhave, Swati Y.\& Saini, Sunil. 2009. Anger Management. Los Angeles: Sage

Hidayati, N dan Erwan, A. 2018. Analisa Perilaku Lalu Lintas Pengguna Jalan di Sekitar Simpang Gendengan Surakarta. Laporan Riset: Hibah Penelitian Traffic Accident Research Center. Direktorat Keamanan dan Keselamatan Korlantas Polri. http://www.korlantas-irsms.info

Jamaludin, A.N. 2015. Sosiologi Perkotaan: Memahami Masyarakat Kota dan Problematikanya. CV Pustaka Setia. Bandung

Javadi SMH., Azad HF., Tahmasebi S., Rafiei H., Rahgozar M., Tajlili A. 2015. Study of Psycho-Social Factors Affecting Traffic Accidents Among Young Boys in Tehran. Iran Red Crescent Medical Journal. 17 (7).

Mohanty, Malaya dan Gupta, Ankit. 2015. Factors Afeecting Road Crash Modeling. Journal of Transport Literature, 9 (2), 15-19, April 2015. www.journal-of-transportliterature.org

Nas, P. J. M. 1986. The Indonesian city: studies in urban development and planning, Dordrecht, Holland; Cinnaminson, U.S.A., Foris Publication

Peden, M., Scurfield, R., David Sleet, Mohan, D., Hyder, A.A., Jarawan, E. and Mathers, C. (eds.). 2004. World report on road traffic injury prevention. Geneva: World Health Organization.

Satlantas Polresta Surakarta. Data Kecelakaan dan Pelanggaran Lalu Lintas (unpublished).

Siregar, Aswin A. 2018. How Can Speed Enforcement be Made More Effective? An investigation into the effect of police presence, speed awareness training and roadside publicity on drivers' choice of speed. Ph.D. Thesis. University of Leeds. The United Kingdom. 